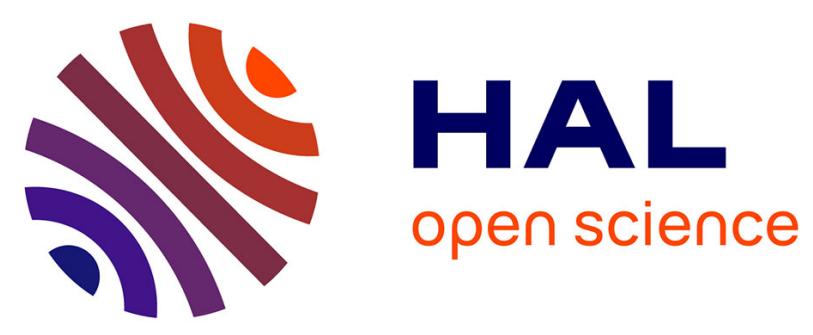

\title{
Using terrestrial laser scanning data to estimate large tropical trees biomass and calibrate allometric models: A comparison with traditional destructive approach
}

Stephane Momo Takoudjou, Pierre Ploton, Bonaventure Sonké, Jan Hackenberg, Sebastien Griffon, Francois Rouault de Coligny, Narcisse Guy

Kamdem, Moses Libalah, Gislain Ii Mofack, Gilles Le Moguedec, et al.

\section{To cite this version:}

Stephane Momo Takoudjou, Pierre Ploton, Bonaventure Sonké, Jan Hackenberg, Sebastien Griffon, et al.. Using terrestrial laser scanning data to estimate large tropical trees biomass and calibrate allometric models: A comparison with traditional destructive approach. Methods in Ecology and Evolution, 2018, 9 (4), pp.905-916. 10.1111/2041-210X.12933 . hal-01837401

\author{
HAL Id: hal-01837401 \\ https://hal.science/hal-01837401
}

Submitted on 26 May 2020

HAL is a multi-disciplinary open access archive for the deposit and dissemination of scientific research documents, whether they are published or not. The documents may come from teaching and research institutions in France or abroad, or from public or private research centers.
L'archive ouverte pluridisciplinaire HAL, est destinée au dépôt et à la diffusion de documents scientifiques de niveau recherche, publiés ou non, émanant des établissements d'enseignement et de recherche français ou étrangers, des laboratoires publics ou privés. 


\title{
Using terrestrial laser scanning data to estimate large tropical trees biomass and calibrate allometric models: A comparison with traditional destructive approach
}

\author{
Stéphane Momo Takoudjou ${ }^{1,2}$ (i) | Pierre Ploton $^{2}$ | Bonaventure Sonké ${ }^{1}$ | \\ Jan Hackenberg ${ }^{3,4}$ | Sébastien Griffon ${ }^{2}$ | Francois de Coligny ${ }^{2}$ | Narcisse Guy Kamdem ${ }^{1}$ \\ Moses Libalah $^{1}$ | Gislain II Mofack ${ }^{1}$ | Gilles Le Moguédec ${ }^{2}$ | Raphaël Pélissier ${ }^{2}$ | \\ Nicolas Barbier ${ }^{1,2}$
}

\begin{abstract}
${ }^{1}$ Plant Systematic and Ecology Laboratory, Higher Teacher's Training College, University of Yaoundé I, Yaoundé, Cameroon

${ }^{2}$ Botany and Modelling of Plant Architecture and Vegetation (AMAP) Laboratory, French National Research Institute for Sustainable Development (IRD), Center for International Cooperation in Agricultural Research for Development (CIRAD), Scientific Research National Center (CNRS), Institut national de la recherche agronomique (INRA), Montpellier University, Montpellier, France

${ }^{3}$ Unité Biogéochimie des Ecosystèmes Forestiers (BEF), INRA, Champenoux, France ${ }^{4}$ Laboratory of Forest Inventory (LIF), Institut National de l'Information Géographique et Forestière (IGN), Nancy, France
\end{abstract}

\section{Correspondence}

Stéphane Momo Takoudjou

Email: takoudjoumomo@gmail.com

\section{Funding information}

Global Environment Facility, Grant/Award Number: TF010038; World Bank; French Government scholarship

Handling Editor: Sean McMahon

\section{Abstract}

1. Calibration of local, regional or global allometric equations to estimate biomass at the tree level constitutes a significant burden on projects aiming at reducing Carbon emissions from forest degradation and deforestation. The objective of this contribution is to assess the precision and accuracy of Terrestrial Laser Scanning (TLS) for estimating volumes and above-ground biomass (AGB) of the woody parts of tropical trees, and for the calibration of allometric models.

2. We used a destructive dataset of 61 trees, with diameters and AGB of up to $186.6 \mathrm{~cm}$ and $60 \mathrm{Mg}$ respectively, which were scanned, felled and weighed in the semi-deciduous forests of eastern Cameroon. We present an operational approach based on available software allowing the retrieving of TLS volume with low bias and high accuracy for large tropical trees. Edition of the obtained models proved necessary, mainly to account for the complexity of buttressed parts of tree trunks, which were separately modelled through a meshing approach, and to bring a few corrections in the topology and geometry of branches, thanks to the AMAPSTUDIO-scan software.

3. Over the entire dataset, TLS-derived volumes proved highly reliable for branches larger than $5 \mathrm{~cm}$ in diameter. The volumes of the remaining woody parts estimated for stumps, stems and crowns as well as for the whole tree proved very accurate (RMSE below $2.81 \%$ and $R^{2}$ above of .98) and unbiased. Once converted into AGB using mean local-specific wood density values, TLS estimates allowed calibrating a biomass allometric model with coefficients statistically undistinguishable from those of a model based on destructive data. The Unedited Quantitative Structure Model (QSM) however leads to systematic overestimations of woody volumes and subsequently to significantly different allometric parameters.

4. We can therefore conclude that a non-destructive TLS approach can now be used as an operational alternative to traditional destructive sampling to build the allometric equations, although attention must be paid to the quality of QSM model adjustments to avoid systematic bias. 
KEYWORDS

above-ground biomass, allometric equation, Central Africa, Congo Basin, REDD+, terrestrial-laser scanner, tropical forest trees

\section{1 | INTRODUCTION}

Tropical forest is expected to play a pivotal role in the mitigation of climate change (Houghton, Byers, \& Nassikas, 2015) by offsetting the carbon released by the use of fossil fuels, whereas methods to estimate forest biomass remain very tedious and impractical. To assess carbon stocks over large areas of forests, all methods, either samplebased (e.g. Maniatis et al., 2011) or remote sensing based (e.g. Baccini et al., 2012), are dependent on above-ground biomass (AGB) estimations in forest sample plots to derive larger scale statistics.

As long as harvesting and weighing complete forest plots remain impractical (but see Clark \& Kellner, 2012), and no other method allows to directly measure AGB at the plot level in dense tropical forests (Raumonen et al., 2013, 2015; Tao, Wu, et al., 2015; Trochta, Kruček, Vrška, \& Kraâl, 2017), the estimation of forests plot AGB and the associated error largely depend on tree-level AGB prediction models (Chave et al., 2004; Picard, Boyemba Bosela, \& Rossi, 2015). The latter are calibrated on destructive datasets and combine easily as measurable tree descriptors-typically diameter at breast height $(\mathrm{DBH})$, tree height $(\mathrm{H})$ and wood density (WD)-to derive tree AGB estimate. Calibrating an AGB model requires to account for a number of factors known to affect allometric relationships, such as tree architecture (Goodman, Phillips, \& Baker, 2014; Ploton et al., 2016), species wood density (e.g. Bastin, Fayolle, et al., 2015; Chave et al., 2005, 2014; Zanne et al., 2009), edaphic and climatic contraints (e.g. Chave et al., 2014), interactions from neighbouring trees (e.g. Feldpausch et al., 2012), to name only a few. Obtaining a representative sample accounting for all these effects across all size classes may prove to be not only a costly and daunting task, but also a damaging one if not altogether unauthorised in sensitive or protected areas. To compensate for some of the limitations of existing models, accurate data from remote sensing are needed (e.g. Clark \& Kellner, 2012; van Leeuwen \& Nieuwenhuis, 2010) and new descriptors are progressively being added to improve current allometric models (e.g. Figueiredo, d'Oliveira, Braz, de Almeida Papa, \& Fearnside, 2016; Goodman et al., 2014; Ploton et al., 2016). Another drawback of the destructive approach is that it is impossible to go back and add new measurements to previously felled trees. To make matters worse, trees that contribute the most to forest standing biomass, as well as its temporal and spatial variations, are the largest ones (e.g. Bastin, Barbier, et al., 2015), and thus the hardest to sample. Weighing a tropical tree of up to 100 tons of fresh mass with only a few scales and chainsaws indeed require quite a bit of time and manpower (185 men-days for our largest tree!). Therefore, large trees are under-represented in the pantropical dataset model (Chave et al., 2014), which has for consequence to introduce biases in tree- and plot-level AGB predictions (e.g. Ploton et al., 2016).
For about a decade, a growing number of studies have been using three-dimensional points clouds of trees from Terrestrial Laser Scanning (TLS) technology to estimate above-ground tree volume (e.g. Bournez, Landes, Saudreau, Kastendeuch, \& Najjar, 2017; Calders et al., 2015; Côté, Fournier, \& Egli, 2011; Hackenberg, Morhart, Sheppard, Spiecker, \& Disney, 2014; Hackenberg, Spiecker, Calders, Disney, \& Raumonen, 2015; Hackenberg, Wassenberg, Spiecker, \& Sun, 2015; Mei, Zhang, Wu, Wang, \& Zhang, 2017; Raumonen et al., 2013; Tansey, Selmes, Anstee, Tate, \& Denniss, 2009) based on a variety of tree reconstruction methods like the Quantitative Structure Model (QSM) and Outer Hull Model (Stovall, Vorster, Anderson, Evangelista, \& Shugart, 2017). Tree models volume and derived AGB estimates usually correlates well with validation data (Table 1). Hence, TLS data is often thought of as a promising, nondestructive alternative to traditional data for AGB models calibration. Until now however, most studies focused on relatively small temperate trees bearing needle leaves or at the leafless stage (Table 1), while the accuracy of a tree model is expected to decrease (1) when tree size increases, because of a lower point cloud quality in the tree crown (e.g. occlusions of high branches from low branches, occlusion of the upper side of branches from their own lower side) and/or the development of more complex geometrical shapes (e.g. buttresses) and (2) in dense, evergreen forests, because of the higher level of occlusion of tree woody structure by leaves and surrounding vegetation (neighbouring trees and bushes, lianas, etc.). Whether TLS technology can readily be used to estimate large tropical canopy trees biomass and build accurate allometric equations remains an open question. Hence, our study focusses on measurements at the individual level, as much remains to be done there in terms of error quantification, as well as the exploration of tree structure and growth patterns. Our objective is, therefore, to make the most of TLS data to estimate volumes and AGB on individual large tropical trees (>10 Mg), from a range of structurally contrasted species, based on open (SIMPLETREE) and broadly available software, under careful user supervision. We test a semi-automated processing chain going from field data acquisition to the estimation of above-ground wood volume and AGB. Intermediate step is implemented in the chain to identify sources of error and bias in the QSM and allow for their correction, notably using the AMAPSTUDIO-Scan (ASSc): an open-access and interactive software developed specifically for this purpose (http://amapstudio.cirad.fr/). We further use TLS-derived AGB estimates to calibrate an allometric model, and compare this model to its counterpart calibrated on destructive data.

\section{2 | MATERIALS AND METHODS}

\section{1 | Study area}

The study was conducted in the Eastern of Cameroon, in the Ndélélé district $\left(4^{\circ} 02^{\prime} 20.77^{\prime \prime} \mathrm{N}\right.$ and $\left.14^{\circ} 55^{\prime} 49.15^{\prime \prime} \mathrm{E}\right)$, within Forest 


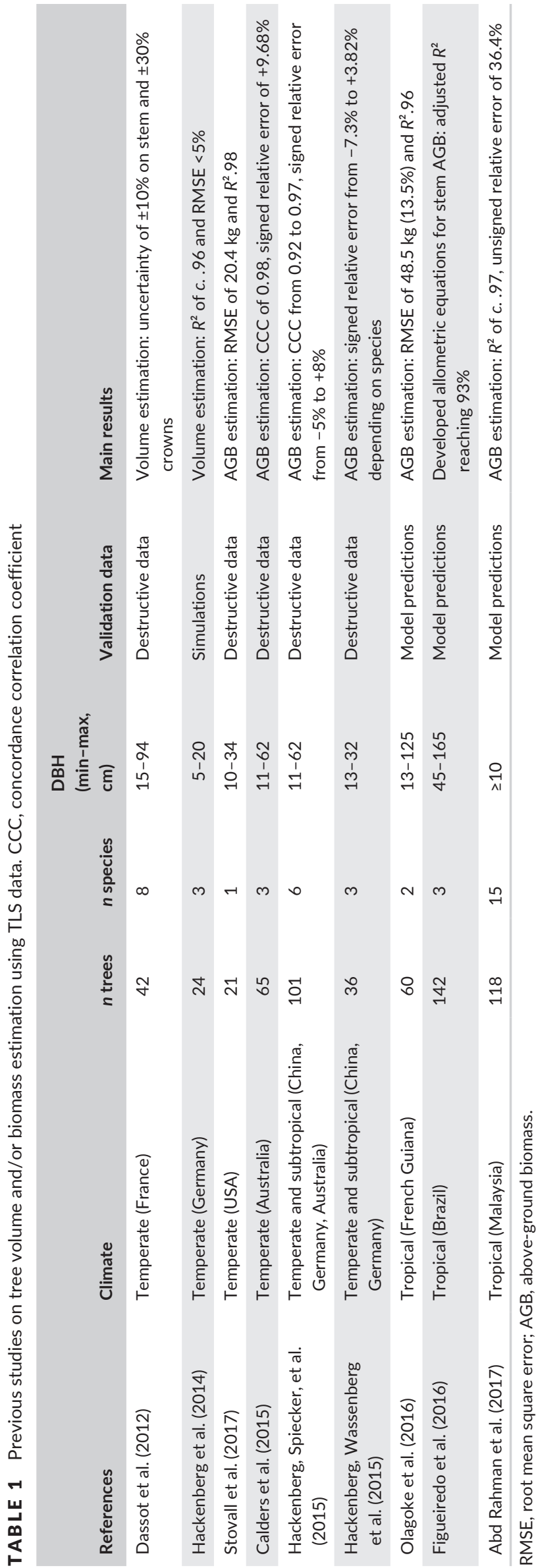

Management Unit 10-051. Forests in the area are classified into semideciduous and dominated by species of Malvaceae and Canabaceae (Letouzey, 1985). The chosen trees were not peculiar trees outside the forest, but were generally picked to be visible and not covered by lianas. Most large trees present buttressed or fluted trunks. Average annual precipitations range between 1500 and $2000 \mathrm{~mm}$ with two marked dry seasons and the average annual temperature is $24^{\circ} \mathrm{C}$. Elevation ranges between 600 and $700 \mathrm{~m}$ a.s.l. Ferralitic red soils characterise the non-hydromorphic parts of the area (Gartlan, 1989).

\section{2 | Tree sampling}

Between July 2015 and August 2016, we scanned 61 trees, a few days before they were felled and their AGB destructively estimated. Scanned trees, which were selected to cover large ranges of tree sizes and species-averaged wood density, belong to fifteen different species and have a mean height $(H)$ of $33.72 \mathrm{~m}( \pm 12.41)$ and a mean DBH) of $58.37 \mathrm{~cm}( \pm 41.30)$ (details in Table 2).

\subsection{Estimation of tree volume and above-ground biomass from destructive data}

Felled trees were stratified into four compartments: stump, stem, branches and leaves (including any reproductive parts). When a segment's basal diameter was smaller than $70 \mathrm{~cm}$, its green mass was obtained by direct weighing. For larger diameters, we used an indirect mass estimation approach combining volume and wood density estimates. In the latter case, the volume of each segment of $1 \mathrm{~m}$ long (in $\mathrm{cm}^{3}$ ) was estimated, using the Smalian formula. For each woody compartment (indiced k), a 3- to 5-cm thick circular wood sample was taken at the extremity of one of the segments and its wood density $\left(W D_{k}\right.$ in g/ $\mathrm{cm}^{3}$, defined as the oven-dried mass per unit of green volume) and anhydrous rate $\left(r_{k}\right.$, defined as the oven-dried mass per unit of green mass) were estimated in the laboratory after drying to constant mass. $W D_{k}$ and $r_{k}$ were used to convert the green mass (from direct weighting) or green volume of compartment $k$ into dry mass. The total tree woody biomass (denoted $\mathrm{AGB}_{\text {dest, }}$, in $\mathrm{Mg}$ ) was obtained by summing the dry mass of all segments in the tree. The woody biomass was also summed separately for each compartment. We computed $b_{k}$, defined as the ratio of green volume over green mass for a wood sample in compartment $k$, to convert direct weightings of a segment's green mass into its green volume and thus compute woody volume at the total tree and compartment levels (denoted $V_{\text {dest }}$ ) for comparison with TLS estimations.

\subsection{Estimation of tree volume and above-ground biomass from TLS data}

\subsection{1 | TLS data collection}

We used a Leica C10 Scanstation for TLS data acquisitions. It is a timeof-flight scanner system working at a $532 \mathrm{~nm}$ wavelength. The laser footprint size is $4.5 \mathrm{~mm}$ in the collimated range $(50 \mathrm{~m})$ and starts diverging afterward. The scanner possesses a large field of view $\left(360^{\circ}\right.$ 
TABLE 2 Taxonomic information, number of sample trees per species $(n)$ and dendrometric parameters of sampled species (maximum and minimum of $\mathrm{DBH}$ and $\mathrm{H}$ )

\begin{tabular}{|c|c|c|c|c|c|c|}
\hline Species & Family & $n$ & \multicolumn{2}{|c|}{$\mathrm{DBH}(\mathrm{cm})$} & \multicolumn{2}{|l|}{$H(\mathrm{~m})$} \\
\hline Annickia chlorantha (Oliv.) Setten \& Maas & Annonaceae & 3 & 10.8 & 35.6 & 12.6 & 35.5 \\
\hline Baphia leptobotrys Harms & Leguminosae & 3 & 33.3 & 84.7 & 16.5 & 31.1 \\
\hline Cylicodiscus gabunensis Harms & Leguminosae & 5 & 13.3 & 173.8 & 17.6 & 53.6 \\
\hline Eribroma oblongum (Mast.) Pierre ex A. Chev. & Malvaceae & 4 & 17.4 & 105.6 & 22.2 & 46.5 \\
\hline Erythrophleum suaveolens (Guill. \& Perr.) Brenan & Leguminosae & 5 & 21.9 & 119.6 & 26.4 & 46.9 \\
\hline Macaranga barteri Müll.Arg. & Euphorbiaceae & 2 & 25.3 & 33.7 & 26.6 & 28.4 \\
\hline Mansonia altissima (A. Chev.) A. Chev. & Malvaceae & 3 & 24.9 & 60.6 & 22.3 & 42.5 \\
\hline Pycnanthus angolensis (Welw.) Warb. & Myristicaceae & 4 & 11.2 & 55.5 & 8.7 & 33.5 \\
\hline Terminalia superba Engl. \& Diels & Combretaceae & 9 & 12.5 & 112.6 & 16.2 & 51.4 \\
\hline Triplochiton scleroxylon K.Schum. & Malvaceae & 6 & 25.4 & 186.6 & 27.4 & 52.8 \\
\hline
\end{tabular}

horizontal, $270^{\circ}$ vertical) and has a scan rate of 50,000 points per s. Scanning resolution was set to a spacing of $0.05 \mathrm{~m}$ between points at $100 \mathrm{~m}$. In the field, at least three scans were performed around each tree after minimal clearing of the forest undergrowth to remove some shrubs (below $5 \mathrm{~cm} \mathrm{DBH}$ ) masking our reference targets.

\subsubsection{General workflow for TLS data processing}

Figure 1, summarises the workflow followed in this study from the raw TLS point cloud to volume estimation.

Co-registration of point clouds from the different scanning positions and extraction of individual trees were performed using the Leica CYCLONE software (v. 9.1). For each tree, we manually removed leaves from the point cloud (step A), which required between 1 and $15 \mathrm{hr}$ per tree depending on its size. This step was performed using standard CYCLONE tools. The processing chain on the remaining woody parts then included: the automated reconstruction of tree topology and structure with the SIMPLETREE software (step B), resulting in unedited Quantitative Structure Models (QSMs); when necessary, manual improvements were performed on (1) stem and crown models using AMAPSTUDIO-Scan (ASSc) software (step C2) and (2) stump models using meshing in the GEOMAGIC software (step C1), resulting in improved QSMs.

\subsection{3 | TLS data processing}

\section{Step B: Automatic volume estimation with SIMPLETREE}

The SIMPLETREE software was used to generate unedited QSMs of individual trees (Hackenberg, Spiecker, et al., 2015). Parameters used for this purpose varies with the points cloud density and the tree size. We faced two main problems when applying SIMPLETREE to our point clouds. Due to the presence of large buttresses on some canopy trees, the circle fitting routine (i.e. Random Sample Consensus or RANSAC method, Fischler \& Bolles, 1981) often returned circles located between two buttresses, that is, outside the wooden part of the tree. We therefore adapted the method described in Hackenberg, Spiecker, et al. (2015) by dividing point clouds into two subsections that were treated differently in the analyses: a lower part composed of trees stumps and all buttresses and an upper, buttresses-free part. As no branches were located in the lower part of the trees, a simpler but more robust reconstruction method could be applied: the cloud was subdivided into slices of a user given thickness (here 0.5-3 m). Each slice was converted to a $2 \mathrm{D}$ cloud in the $\mathrm{x}, \mathrm{y}$ plane and a circle was fitted to it using the Maximum Likelihood Sample Consensus algorithm (Torr \& Zisserman, 2000). For each model, the average distance between the point cloud and the cylinder model was computed and the model with the lowest distance was chosen. The upper part of the tree cloud showed a sufficient quality to be modelled with the SIMPLETREE method without modifications (Hackenberg, Spiecker, et al., 2015) and both cylinder models were connected afterwards. All parameters used to produce unedited QSMs can be found inside SIMPLETREE output txt files for each tree which will be made available online. The principal parameters used to adjust unedited QSMs in SIMPLETREE were [with typical value range] are: sphereMultiplier [3.00 to 6.00]; espClusterStem [0.020 to 0.400]; espClusterBranch [0.008 to 0.02]; espSphere [0.020 to 0.120]. Please refer to Hackenberg et al. $(2014,2015)$ for more information's about these parameters.

\section{Step C: Manual improvement of tree volume estimations}

We used Geomagic Studio 12, to improve volume estimations on tree stumps with a surface meshing approach (wrap tool). Mesh models 


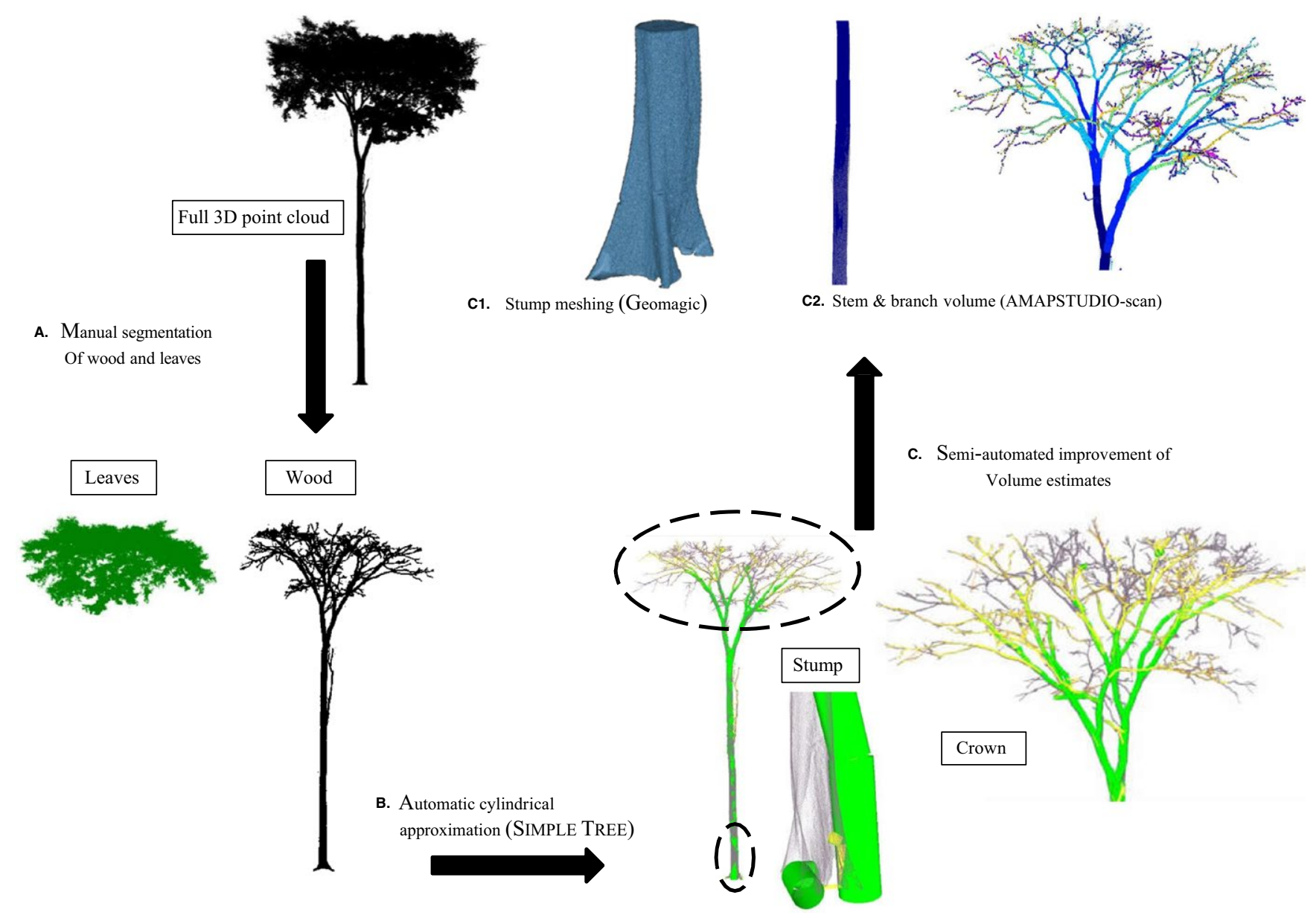

FIGURE 1 Workflow for woody volume estimation

were rendered 'water proof' by closing all remaining holes. The robustness of this process to describe the complex geometry of stumps depends on the point cloud quality (density of points, number of scanning position around the target trees).

We also used ASSc to improve the quality of QSMs in remaining parts of the trees (stems and crowns). It may be used to manually edit the results of automatic QSM algorithms such as SIMPLETREE, allowing the user to fix incomplete or incorrect structures in a tree branching network. The plant model is displayed over the point cloud and represented as a tree graph with vertices and edges. Each vertex is defined by a disk (a centre, a radius and a normal) and edges by two vertices and an axis identifier. The user can manually add vertices and edges, typically to fill-in the plant model in occluded areas or at the crown top, where small branches are only described with very few points. A new vertex can be added by drawing a rough centre, radius and specifying an adjustment approach (ellipse fitting, ellipsoid fitting, projected convex hull) in order to visually optimise the results based on local characteristics of the point cloud.

\subsection{4 | Tree volume and above-ground biomass estimations from Quantitative Structure Models}

Tree compartments (i.e. stump, stem, and crown) and whole tree volume were obtained by summing the volume of corresponding cylinders. Volumes were converted to biomass (denoted $\mathrm{AGB}_{\mathrm{TLS}}$ ) using wood density values (WD, $\mathrm{g} / \mathrm{cm}^{3}$ ) either from global wood density database $\left(W D_{b}\right)$ (Zanne et al., 2009) or from local speciesaveraged wood density taken on the stumps $\left(W D_{\text {dest }}\right)$. In $W D_{\text {dest }}$, only WD samples from tree stumps (i.e. sampled at approximately breast height) were considered, to simulate what one may obtain using wood cores sampled on standing trees.

\section{5 | Statistical analyses}

\subsubsection{Comparison of TLS and destructive estimates}

Assessing the size threshold for the detection of small branches To assess possible signal attenuation below a certain size threshold, we looked for breakpoints in the segment diameter frequency distribution across the whole dataset. A bin size of $0.5 \mathrm{~cm}$ was used to compute the frequency distribution of segment diameters in QSM trees. Following the metabolic theory of ecology (Enquist, West, \& Brown, 2009), the segment diameter-abundance relationship is expected to follow a power law distribution. Strong deviations from this general trend for some size ranges should be the result of a bias in detection (indicating a limitation of the TLS method to capture the smallest branches). We used a two steps breakpoint identification procedure to test whether the scaling of 
segment abundance against diameter changed with segment diameter (Muggeo, 2003). First, we used the Davies' test (Davies, 1987), to detect the presence of significant changes in the slope of the log-linear model for regularly spaced segment diameter values. Second, we used the segment diameter corresponding to the most significant breakpoint as a starting value in a segmented regression (using the "SEGMENTED" package), yielding a more accurate estimate of the segment diameter breakpoint value. Segments below the identified breakpoint where then discarded from comparative analyses between TLS and destructive data.

\section{Comparison of TLS and destructive estimates}

We compared estimates of volume and biomass at the compartment and whole tree levels between destructive $\left(V_{\text {dest }}\right.$ and $\left.A G B_{\text {dest }}\right)$ and TLS-derived estimates $\left(V_{T L S}\right.$ and $\left.A_{G G} B_{T L S}\right)$. Comparisons were performed using linear regression models, characterised by classical fit metrics ( $R^{2}$, RMSE). Method bias ( $\bar{b}$ in \%) was evaluated as the mean of signed relative errors $\left(b_{i}\right.$ in \%) (1):

$$
b_{i}=\left(\frac{X_{\mathrm{TLS}_{i}}-X_{\text {dest }_{i}}}{X_{\text {dest }_{i}}}\right) \times 100
$$

with $X_{\mathrm{TLS}}$ the volume or mass estimate derive from TLS data and $X_{\text {dest }}$ the volume or biomass estimate derived from destructive data.

We also reported the mean $(\bar{s})\left(s_{i}\right.$ in \%) for evaluating the accuracy of TLS estimates (2):

$$
s_{i}=\left|b_{i}\right|
$$

\subsection{2 | Comparison of allometric models}

A standard allometric model (Chave et al., 2014) was calibrated with TLS (unedited or edited QSMs) and destructive data to estimate the consistency between the different methods for building AGB prediction models.

$$
\log 10(A G B)=\alpha+\beta \times \log 10\left(\mathrm{DBH}^{2} \times \mathrm{H} \times \mathrm{WD}\right)+\varepsilon,
$$

with $A G B$ (in $M g$ ) representing either the AGB derived from TLS edited QSM (AGB $\left.{ }_{T L S}\right)$, TLS unedited QSM (AGB' $\left.{ }^{\prime}{ }_{T L S}\right)$ or destructive data $\left(A_{G B} B_{\text {dest }}\right), \mathrm{DBH}$ (in $\mathrm{cm}$ ) and $\mathrm{H}$ (in $\mathrm{m}$ ) derived from TLS $\left(\mathrm{DBH}_{\mathrm{TLS}}\right.$ and $\left.H_{\text {TLS }}\right)$ and from destructive $\left(\mathrm{DBH}_{\text {dest }}\right.$ and $\left.H_{\text {dest }}\right)$ data, WD the local species-averaged wood density taken on the stumps $\left(\mathrm{WD}_{\text {dest }}\right)$ or from the individual wood density taken from all compartments $\left(W D_{\text {ind }}\right)$ and $\varepsilon$ the residual error term in each model $\left(\varepsilon_{\mathrm{TLS}}, \varepsilon^{\prime}{ }_{\mathrm{TLS}}\right.$ and $\left.\varepsilon_{\text {dest }}\right)$, assumed to follow a normal distribution.

To compare pairs of slopes $\left(\beta_{\mathrm{TLS}}\right.$ and $\beta_{\text {dest }} ; \beta^{\prime}{ }_{\mathrm{TLS}}$ and $\left.\beta_{\text {dest }}\right)$ and pairs of intercepts ( $\alpha_{\text {TLS }}$ and $\alpha_{\text {dest }} ; \alpha^{\prime}{ }_{\text {TLS }}$ and $\alpha_{\text {dest }}$ ) of equation 3, we simultaneously fitted the equation with destructive and TLS-derived estimations in the same model. Since pairs of estimates came from the same individuals, the residual variance could no more be supposed independent. We modelled this dependence as follows:

$$
\left(\begin{array}{c}
\varepsilon_{\mathrm{TLS}_{i}} \\
\varepsilon_{\text {dest }_{i}}
\end{array}\right)_{\sim}^{\mathrm{iid}} N\left(\left[\begin{array}{l}
0 \\
0
\end{array}\right],\left[\begin{array}{cc}
\sigma_{\mathrm{TLS}}^{2} & \rho * \sqrt{\sigma_{\mathrm{TLS}}^{2}+\sigma_{\text {dest }}^{2}} \\
\rho * \sqrt{\sigma_{\mathrm{TLS}}^{2}+\sigma_{\text {dest }}^{2}} & \sigma_{\text {dest }}^{2}
\end{array}\right]\right)
$$

with iid = independently and identically distributed, $\rho$ the coefficient of correlation between the residuals of the two methods and the following hypotheses:

1. $h o_{1}: \alpha_{\text {dest }}$ and $\beta_{\text {dest }}=0$

2. $h_{2}: \Delta 1=\alpha_{\text {dest }}-\alpha_{\mathrm{TLS}}=0$ and $\Delta 2=\beta_{\text {dest }}-\beta_{\mathrm{TLS}}=0$

3. $h^{\prime} \mathrm{O}_{2}: \Delta^{\prime} 1=\alpha_{\text {dest }}-\alpha_{\mathrm{TLS}}^{\prime}=0$ and $\Delta^{\prime} 2=\beta_{\text {dest }}-\beta_{\mathrm{TLS}}^{\prime}=0$

All analyses were performed in R statistical software ( $R$ Development Core Team, 2015), using the Nonlinear Mixed-effects Models (nlme) package and the Generalised Least Squares ( $g / s)$ function to test hypotheses $\left(h o_{1}, h o_{2}, h^{\prime} o_{2}\right)$, at the alpha risk level of $5 \%$.

\section{3 | RESULTS}

\section{1 | Signal saturation on small branches}

A significant breakpoint was evidenced in the segment diameter density distribution at $4.5 \mathrm{~cm}$ (Figure 2a). Testing the effect of species or tree size $(\mathrm{DBH})$ on the breaking point value did not yield significant results, suggesting that tree architecture or size had no effect on the precision of the scans, but also in part because fitting often failed at individual level. Following these results, segments below $5 \mathrm{~cm}$ in diameter were removed in all subsequent TLS vs destructive data comparisons. The proportion of these small branches was $4.7 \%$ of total tree biomass in the destructive data, and $3.9 \%$ in TLS estimations. The underestimation seemed more pronounced on large individuals, with a proportion of only $0.6 \%$ with TLS against $2.1 \%$ with destructive data for trees of more than $10 \mathrm{Mg}$ (Figure 2b).

\subsection{Estimating compartments and whole tree volume with TLS data}

At the whole tree level, $V_{\text {TLS }}$ derived from unedited SIMPLETREE QSMs led to a large bias ( $\bar{b}$ of $15.29 \%$ ) compared to $V_{\text {dest }}$ (Figure 3a) with a satisfying $R^{2}$ (.75) and a high relative unsigned error ( $\bar{s}$ of $\left.29 \%\right)$. The 95\% confidence interval $(\mathrm{Cl})$ increased proportionally with tree volume and error level reached $\bar{s}=35 \%$ for trees with volumes larger than $20 \mathrm{~m}^{3}$ (corresponding to trees with $\mathrm{DBH} \geq 90 \mathrm{~cm}$ ). At the compartment level, most of the error came from tree crowns $(\bar{s}=84.72 \%)$ and from stumps ( $\bar{s}=45.99 \%$ ). With an $\bar{s}$ value of $26.22 \%$, stems were relatively better described (Figure $4 a-c)$. At the tree level, we realised these relatively large error values were in fact coming from a few errors in the tree models, that could be overcome either by manually editing some connections in the crown, or by modelling the stump separately. Indeed, after editing, $\bar{s}$ decreased to $34.50 \%$ for stumps, $17.24 \%$ for stems and $29.18 \%$ for crowns (Figure $4 d-f$ ).

These improvements were of course passed on the whole tree level (Figure 3b), leading to a $R^{2}$ value of .98, a RMSE of $2.81 \mathrm{~m}^{3}$ and an $\bar{s}$ of $12 \%$. In addition, the $95 \% \mathrm{Cl}$ showed a lesser dependence on tree 
FIGURE 2 Signal attenuation in small branches. (a) Identification of a breaking point in the distribution of segment diameters from the edited QSMs (Quantitative Structure Model), (b) total AGB (above-ground biomass) of segments of diameter smaller than $5 \mathrm{~cm}$ as a function of total tree AGB

FIGURE 3 Comparison of $V_{\text {TLS }}$ against $V_{\text {dest, }}$ dark grey area represents the $95 \%$ confidence interval and the light grey area represents the prediction interval. (a) $V_{\text {TLS }}$ from unedited QSMs (Quantitative Structure Model) against $V_{\text {dest }}{ }$ (b) $V_{\text {TLS }}$ from edited QSMs against $V_{\text {dest }}$
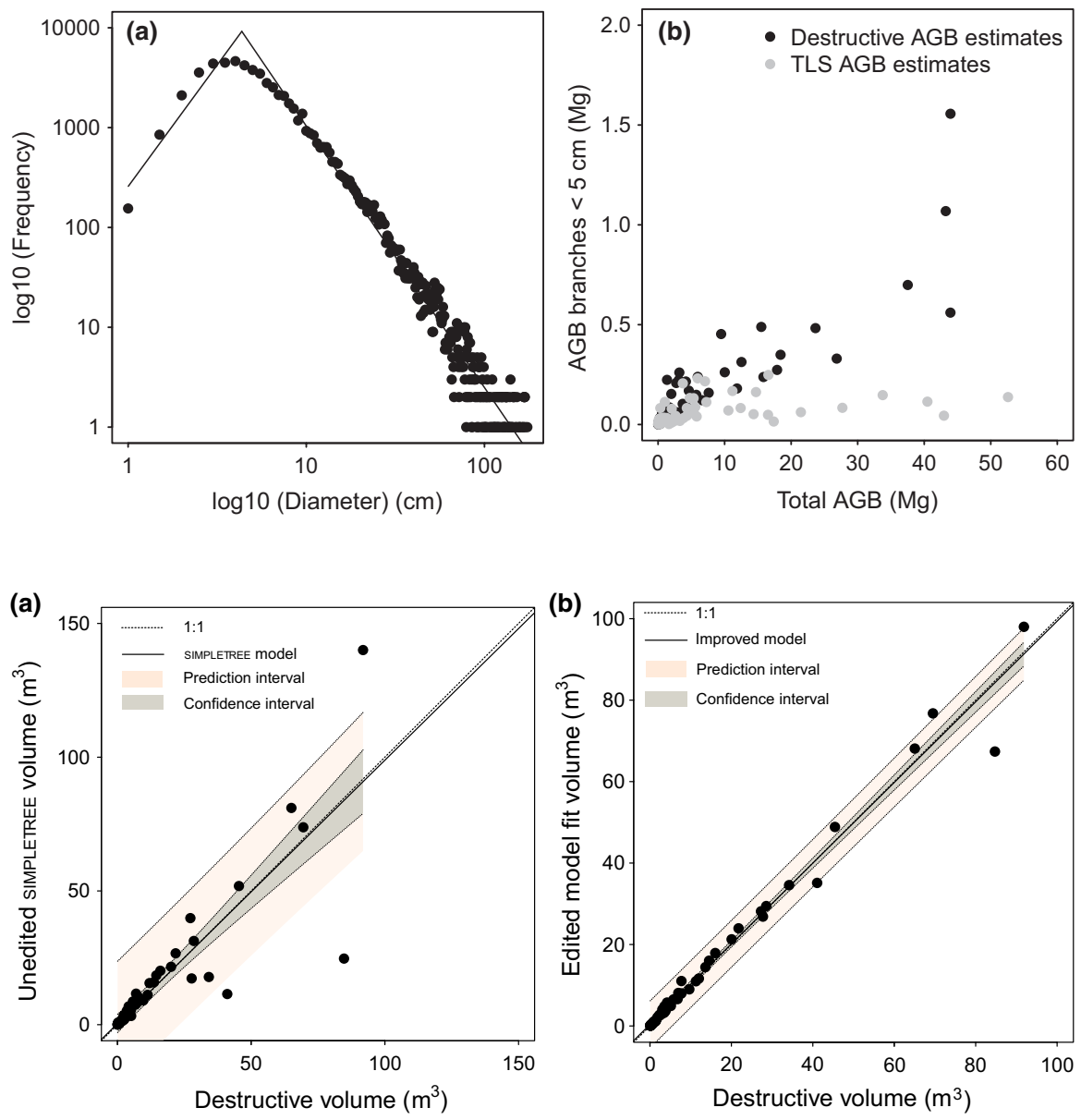

volume, and the estimates showed a remarkable reduction in the bias ( $\bar{b}$ of $4.68 \%$ ) (Details in Table 3).

\section{3 | Above-ground biomass derived from TLS estimates with different wood densities}

When computing $A G B_{T L S}$, the use of local wood density values $\left(W D_{\text {dest }}\right)$ both led to higher goodness-of-fit values, with $R^{2}$ and RMSE values of .97 and $1.78 \mathrm{Mg}$ against .93 and $2.73 \mathrm{Mg}$ with literature values $\left(\mathrm{WD}_{b}\right)$, and reduced bias, as the regression with $\mathrm{AGB}_{\text {dest }}$ happened to be closer to the 1:1 line (Figure 5). We therefore used the local density values in subsequent analyses, although it is worth mentioning that the use of $W D_{b}$ only had a marginal impact on subsequent analyses.

\subsection{Calibrating an allometric model with TLS data}

Allometric models built with either destructive or TLS-derived (edited QSMs) biomass proved visually similar (Figure 6a) and presented nearly identical $R^{2}$ values of .98 and .95 , respectively. Using unedited QSMs to estimate $\mathrm{AGB}_{\mathrm{TLS}}$ led to a slightly inferior $R^{2}(.93)$ and a visual discrepancy between models prediction lines (Figure 6b). Statistical comparisons of allometric models parameters confirmed our visual appraisal (Figure 6a), with no effect of the method (i.e. TLS or destructive) when using edited QSMs (Table S1) and a significant method effect when using unedited QSMs (Table S2).
The coefficients of allometric models adjusted on either destructive or TLS (edited and unedited approach) predictors are summarised in (Table 4).

\section{DISCUSSION AND CONCLUSION}

The development of biomass allometry models has up to now been a daunting task as the traditional destructive approach is timeconsuming and costly. As a result, the error made on ground estimations of trees and forest sample plots biomass (AGB) is among the largest error sources in the forest carbon mapping chain (Ahmed, Siqueira, Hensley, \& Bergen, 2013). The rapid development of Terrestrial Laser Scanner (TLS) applications in forestry, in particular tree reconstruction methods, will soon change the game by providing reference datasets of unprecedented size and spatial representativity for the calibration of allometric models. Yet, the accuracy with which tree AGB can be estimated from current tree reconstruction algorithms has been virtually unexplored in natural tropical forests, in particular for large canopy trees (e.g. $\geq 10 \mathrm{Mg}$ ). While there is a critical need to sample more AGB reference data on large tropical trees (Chave et al., 2005, 2014), such trees may be seen as particularly challenging to reconstruct from TLS data owing to the usual complexity of trunk shapes (e.g. buttresses) and to higher occlusion levels in tree crowns. In this study, we used a large destructive 

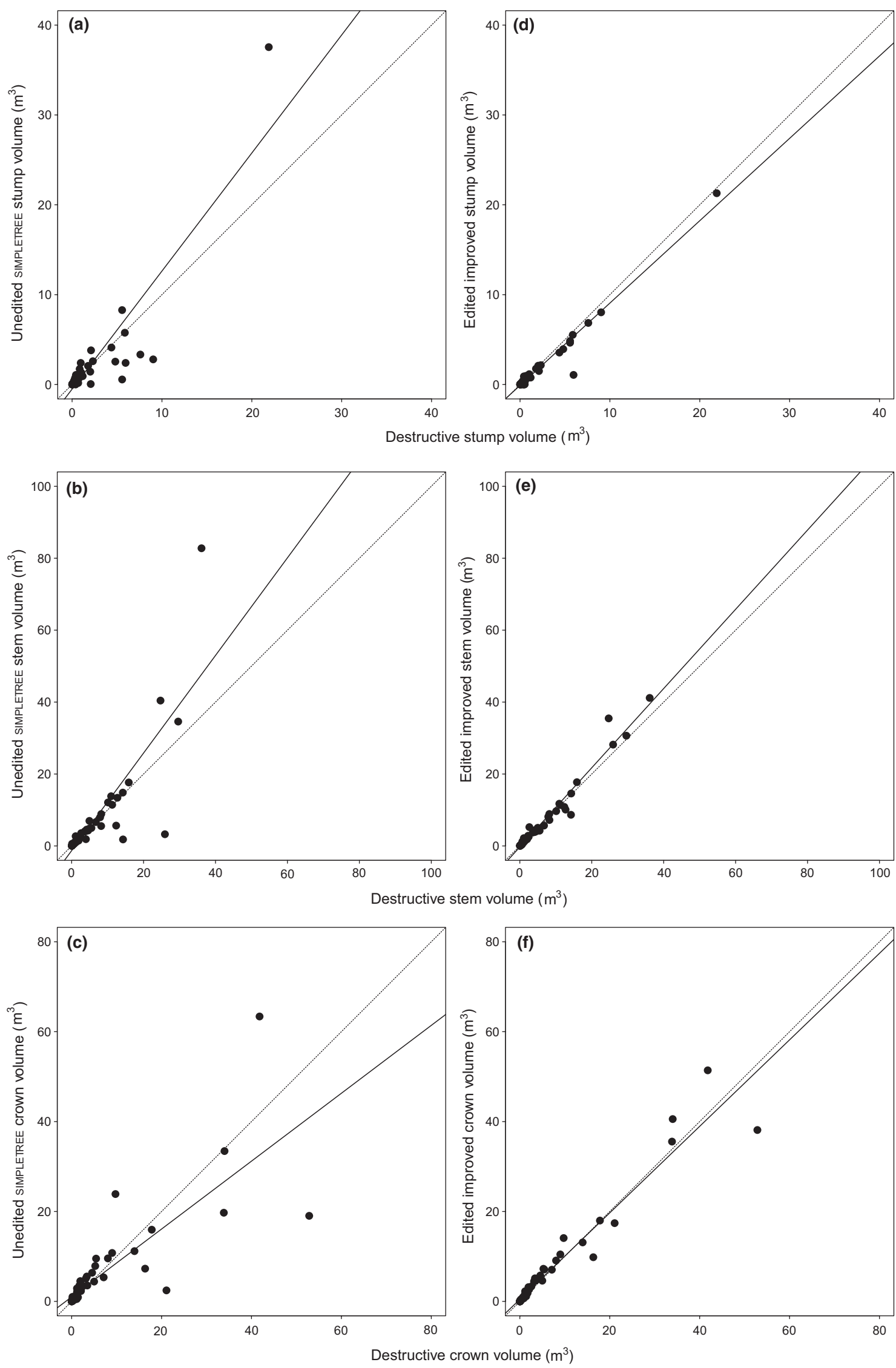

FIGURE 4 Comparison of $V_{\text {TLS }}$ against $V_{\text {dest }}$ for each compartment in function of the methodology: $V_{\text {TLS }}$ from unedited sIMPLETREE QSMs in captions (a), (b) and (c), $V_{T L S}$ from edited QSMs (Quantitative Structure Model) in captions (d), (e) and (f). The 1:1 line is represented as a grey dotted line. Model fit is represented as a full black line 

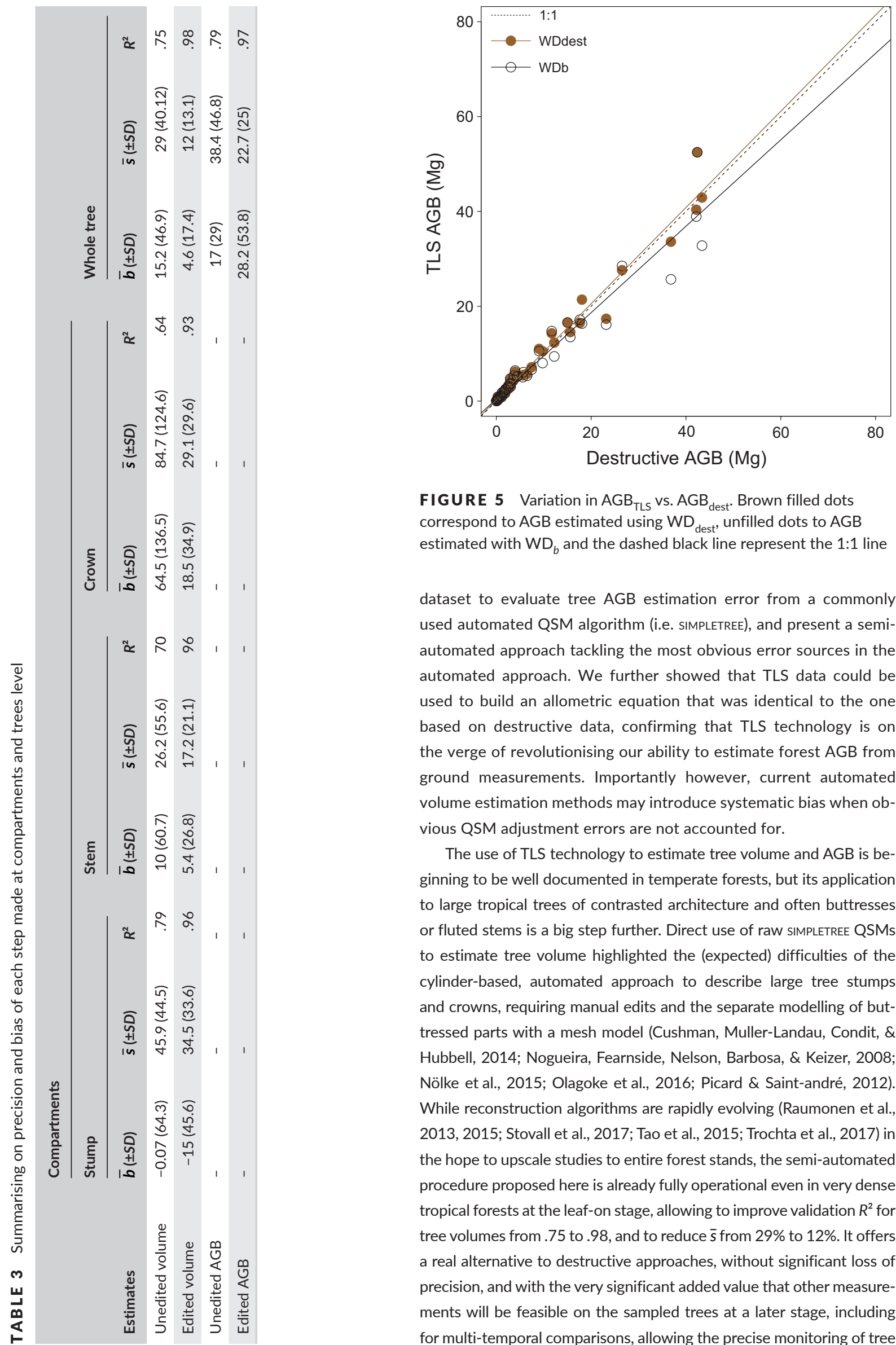

FIGURE 5 Variation in $A_{G B} B_{T L S}$ vs. $A_{G B} B_{\text {dest }}$. Brown filled dots correspond to $A G B$ estimated using $W D_{\text {dest }}$, unfilled dots to $A G B$ estimated with $W D_{b}$ and the dashed black line represent the 1:1 line

dataset to evaluate tree AGB estimation error from a commonly used automated QSM algorithm (i.e. SIMPLETREE), and present a semiautomated approach tackling the most obvious error sources in the automated approach. We further showed that TLS data could be used to build an allometric equation that was identical to the one based on destructive data, confirming that TLS technology is on the verge of revolutionising our ability to estimate forest $A G B$ from ground measurements. Importantly however, current automated volume estimation methods may introduce systematic bias when obvious QSM adjustment errors are not accounted for.

The use of TLS technology to estimate tree volume and AGB is beginning to be well documented in temperate forests, but its application to large tropical trees of contrasted architecture and often buttresses or fluted stems is a big step further. Direct use of raw SIMPLETREE QSMs to estimate tree volume highlighted the (expected) difficulties of the cylinder-based, automated approach to describe large tree stumps and crowns, requiring manual edits and the separate modelling of buttressed parts with a mesh model (Cushman, Muller-Landau, Condit, \& Hubbell, 2014; Nogueira, Fearnside, Nelson, Barbosa, \& Keizer, 2008; Nölke et al., 2015; Olagoke et al., 2016; Picard \& Saint-andré, 2012). While reconstruction algorithms are rapidly evolving (Raumonen et al., 2013, 2015; Stovall et al., 2017; Tao et al., 2015; Trochta et al., 2017) in the hope to upscale studies to entire forest stands, the semi-automated procedure proposed here is already fully operational even in very dense tropical forests at the leaf-on stage, allowing to improve validation $R^{2}$ for tree volumes from .75 to .98 , and to reduce $\bar{s}$ from $29 \%$ to $12 \%$. It offers a real alternative to destructive approaches, without significant loss of precision, and with the very significant added value that other measurements will be feasible on the sampled trees at a later stage, including for multi-temporal comparisons, allowing the precise monitoring of tree 

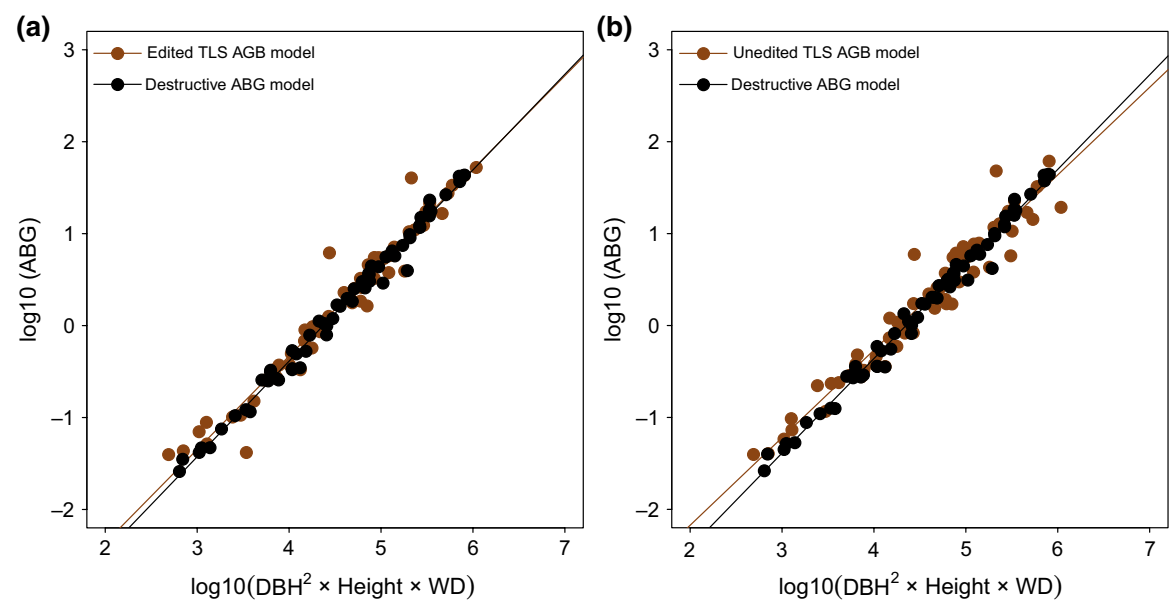

FIGURE 6 AGB (above-ground biomass) allometric models based on TLS data (both AGB estimates and tree biophysical predictors, in grey) and destructive data (in black). (a) AGB estimate from unedited SIMPLETREE volume. (b) AGB estimate from edited SIMPLETREE volume

TAB LE 4 Allometric models for the estimation of tree above-ground biomass (AGB; Mg), calibrated with each method. RMSE is given in Mg

\begin{tabular}{|c|c|c|c|c|c|}
\hline \multirow[b]{2}{*}{ Equation type } & \multicolumn{2}{|c|}{ Model parameters } & \multirow[b]{2}{*}{$R^{2}$} & \multirow[b]{2}{*}{ RMSE } & \multirow[b]{2}{*}{ Approach } \\
\hline & $\beta$ & $\alpha$ & & & \\
\hline $\log 10\left(\mathrm{AGB}_{\text {dest }}\right) \sim \boldsymbol{\beta} \log 10\left(\mathrm{DBH}^{2} \times H \times \mathrm{WD}_{\text {ind }}\right)+\boldsymbol{\alpha}$ & $1.04^{* * *}$ & $-4.54^{* * *}$ & .98 & 10.92 & Destructive \\
\hline $\log 10\left(\mathrm{AGB}_{\mathrm{TLS}}\right) \sim \boldsymbol{\beta} \log 10\left(\mathrm{DBH}^{2} \times H \times \mathrm{WD}_{\text {dest }}\right)+\boldsymbol{\alpha}$ & $1.01^{* * *}$ & $-4.39^{* * *}$ & .95 & 10.95 & Edited \\
\hline $\log 10\left(\mathrm{AGB}_{\mathrm{TLS}}^{\prime}\right) \sim \boldsymbol{\beta}^{\prime} \log 10\left(\mathrm{DBH}^{2} \times H \times \mathrm{WD}_{\text {dest }}\right)+\boldsymbol{\alpha}^{\prime}$ & $0.96^{* * *}$ & $-4.12^{* * *}$ & .93 & 11.01 & Unedited \\
\hline
\end{tabular}

${ }^{* * *} p$-value of test $<.001$.

growth patterns, crown plasticity, interactions with neighbours, etc. (Hosoi, Nakai, \& Omasa, 2013; Kaasalainen et al., 2014; Rochon, 2014).

The precision of the obtained estimates may depend on the correct identification of a size threshold below which branches are too small to be captured. We proposed a simple and objective approach to identify this threshold. This value $(5 \mathrm{~cm})$ is lower than threshold values chosen in previous studies (Dassot, Colin, Santenoise, Fournier, \& Constant, 2012; Hackenberg, Wassenberg, et al., 2015) with cut-off values of $7 \mathrm{~cm}$ and $10 \mathrm{~cm}$. This is all the more impressive if we consider the size, presence of buttresses of the trees analysed here, number of species and the fact they were scanned leaves-on.

Preliminary segmentation of leaves and wood is still necessary to obtain consistent QSMs and volume estimates. The manual segmentation approach adopted here was time consuming, but some existing algorithms as in Hackenberg, Spiecker, et al. (2015), did not yield satisfying results on our trees, although they can be used for preliminary trimming. The geometric and optical properties of leaves and wood are indeed very dependent on the species, hampering the generalisation of segmentation criteria. Therefore, this is a research direction from which we can still expect improvements towards the routine use of TLS data for efficient massive tree volume extraction.

The parameters of allometric models built from TLS and destructive AGB estimates proved statistically undistinguishable, despite all due attention brought to potential bias caused by autocorrelation in the paired data. This is a very important result for tropical countries currently involved in the readiness phase for the REDD+ initiative. TLS approaches will indeed allow to significantly expand sampling efforts for the calibration of allometric models, and allow accounting for regional and local variations in tree form induced by abiotic and biotic effects, particularly on the largest trees, and eventually result in more reliable estimates of carbon stocks and fluxes.

The next challenge is now to automate the treatment chain as much as possible, specifically for the leaf/wood segmentation step (Béland, Baldocchi, Widlowski, Fournier, \& Verstraete, 2014; Tao, Guo, et al., 2015; Tao, Wu, et al., 2015), and also for tree and crown segmentation from full plots TLS-scans (Trochta et al., 2017), to allow for the massive and accurate collection of individual tree volumes (Wilkes et al., 2017). The latter step remains indeed difficult to perform in dense forest stands at the leaf-on stage, because of occlusions and overlap or contacts between neighbouring tree crowns (Raumonen et al., 2013, 2015; Tao, Guo, et al., 2015; Trochta et al., 2017). It is likely that progress in leaf-wood segmentation and tree segmentation will go hand-in-hand. Constant quality control of model estimates will, however, remain necessary to avoid introducing new bias at this level in the processing chain.

\section{ACKNOWLEDGEMENTS}

This study benefited from grant No TF010038 from the Global Environment Facility administered by the World Bank and implemented by the COMIFAC, within the context of subcomponent $2 b$ of PREREDD+ "Establishment of allometric equations for forest types in the Congo Basin" which was executed by the ONFi/TEREA/Nature+ consortium. We are very grateful to the Alpicam-Grumcam company, and in particular D. Bastin, M. Ramoni and C. Pizzutto, for their constant logistical support during this and previous studies. MTS is supported by a French Government scholarship (SCAC) PhD program and by an IRD ARTS grant. We thank P. Ekassi for his driving skills and help in the field. 


\section{CONFLICTS OF INTEREST}

The authors declare no conflicts of interest.

\section{AUTHORS' CONTRIBUTIONS}

Project conception, TLS data collection and analyses: S.M.T., P.P., R.P. and N.B. Destructive data collection: B.S., G.M. and N.G.K. SIMPLETREE: J.H. and S.M.T. AMAPSTUDIO-Scan: S.G., S.M.T. and F.deC. Analysis feedback: All authors. Writing: S.M.T., P.P. and N.B. Writing feedback: P.P., R.P., J.H., M.L., G.L.M., G.M., N.G.K. and B.S.

\section{DATA ACCESSIBILITY}

Data available from the Dryad Digital Repository https://doi. org/10.5061/dryad.10hq7 (Momo Takoudjou et al., 2017).

\section{ORCID}

Stéphane Momo Takoudjou (iD http://orcid.org/0000-0002-1226-4826

\section{REFERENCES}

Ahmed, R., Siqueira, P., Hensley, S., \& Bergen, K. (2013). Uncertainty of forest biomass estimates in North temperate forests due to allometry: Implications for remote sensing. Remote Sensing, 5, 3007-3036. https://doi.org/10.3390/rs5063007

Baccini, A., Goetz, S. J., Walker, W. S., Laporte, N. T., Sun, M., Sulla-Menashe, D., ... Houghton, R. A. (2012). Estimated carbon dioxide emissions from tropical deforestation improved by carbon-density maps. Nature Climate Change, 2, 182-185. https://doi.org/10.1038/nclimate1354

Bastin, J.-F., Barbier, N., Réjou-Méchain, M., Fayolle, A., Gourlet-Fleury, S., Maniatis, D., ... Bogaert, J. (2015). Seeing Central African forests through their largest trees. Scientific Reports, 5, 13156. https://doi. org/10.1038/srep13156

Bastin, J. F., Fayolle, A., Tarelkin, Y., Van Den Bulcke, J., De Haulleville, T., Mortier, F., ... De Cannière, C. (2015). Wood specific gravity variations and biomass of central African tree species: The simple choice of the outer wood. PLoS ONE, 10, e0142146. https://doi.org/10.1371/journal.pone.0142146

Béland, M., Baldocchi, D. D., Widlowski, J. L., Fournier, R. A., \& Verstraete, M. M. (2014). On seeing the wood from the leaves and the role of voxel size in determining leaf area distribution of forests with terrestrial LiDAR. Agricultural and Forest Meteorology, 184, 82-97. https://doi.org/10.1016/j.agrformet.2013.09.005

Bournez, E., Landes, T., Saudreau, M., Kastendeuch, P., \& Najjar, G. (2017). From TLS point clouds to 3D models of trees: A comparison of existing algorithms for 3D tree reconstruction. International Archives of the Photogrammetry, Remote Sensing and Spatial Information Sciences - ISPRS Archives, 42, 113-120. https://doi.org/10.5194/ isprs-archives-XLII-2-W3-113-2017

Calders, K., Newnham, G., Burt, A., Murphy, S., Raumonen, P., Herold M., ... Kaasalainen, M. (2015). Nondestructive estimates of aboveground biomass using terrestrial laser scanning. Methods in Ecology and Evolution, 6, 198-208. https://doi.org/10.1111/2041-210X.12301

Chave, J., Andalo, C., Brown, S., Cairns, M. A., Chambers, J. Q., Eamus, D., ... Yamakura, T. (2005). Tree allometry and improved estimation of carbon stocks and balance in tropical forests. Oecologia, 145, 87-99. https:// doi.org/10.1007/s00442-005-0100-x

Chave, J., Condit, R., Aguilar, S., Hernandez, A., Lao, S., \& Perez, R. (2004). Error propagation and scaling for tropical forest biomass estimates.
Philosophical Transactions of the Royal Society B: Biological Sciences, 359, 409-420. https://doi.org/10.1098/rstb.2003.1425

Chave, J., Réjou-Méchain, M., Búrquez, A., Chidumayo, E., Colgan, M. S., Delitti, W. B. C., ... Vieilledent, G. (2014). Improved allometric models to estimate the aboveground biomass of tropical trees. Global Change Biology, 20, 3177-3190. https://doi.org/10.1111/gcb.12629

Clark, D. B., \& Kellner, J. R. (2012). Tropical forest biomass estimation and the fallacy of misplaced concreteness. Journal of Vegetation Science, 23, 1191-1196. https://doi.org/10.1111/j.1654-1103.2012.01471.x

Côté, J. F., Fournier, R. A., \& Egli, R. (2011). An architectural model of trees to estimate forest structural attributes using terrestrial LiDAR. Environmental Modelling and Software, 26, 761-777.

Cushman, K. C., Muller-Landau, H. C., Condit, R. S., \& Hubbell, S. P. (2014). Improving estimates of biomass change in buttressed trees using tree taper models. Methods in Ecology and Evolution, 5, 573-582. https://doi. org/10.1111/2041-210X.12187

Dassot, M., Colin, A., Santenoise, P., Fournier, M., \& Constant, T. (2012). Terrestrial laser scanning for measuring the solid wood volume, including branches, of adult standing trees in the forest environment. Computers and Electronics in Agriculture, 89, 86-93. https://doi. org/10.1016/j.compag.2012.08.005

Davies, R. B. (1987). Hypothesis testing when a nuisance parameter is present only under the alternative. Biometrika, 74, 33-43.

Enquist, B. J., West, G. B., \& Brown, J. H. (2009). Extensions and evaluations of a general quantitative theory of forest structure and dynamics. Proceedings of the National Academy of Sciences of the United States of America, 106, 7046-7051. https://doi.org/10.1073/pnas.0812303106

Feldpausch, T. R., Lloyd, J., Lewis, S. L., Brienen, R. J. W., Gloor, M., \& Monteagudo Mendoza, A., ... Phillips, O. L. (2012). Tree height integrated into pantropical forest biomass estimates. Biogeosciences, 9, 3381-3403. https://doi.org/10.5194/bg-9-3381-2012

Figueiredo, E. O., d'Oliveira, M. V. N., Braz, E. M., de Almeida Papa, D., \& Fearnside, P. M. (2016). LIDAR-based estimation of bole biomass for precision management of an Amazonian forest: Comparisons of groundbased and remotely sensed estimates. Remote Sensing of Environment, 187, 281-293. https://doi.org/10.1016/j.rse.2016.10.026

Fischler, M. A., \& Bolles, R. C. (1981). Random sample consensus: A paradigm for model fitting with applications to image analysis and automated cartography. Communications of the ACM, 24, 381-395. https:// doi.org/10.1145/358669.358692

Gartlan, S. (1989). La Conservation des Ecosystèmes forestiers du Cameroun. Gland, Switzerland: UICN, I'Alliance mondiale pour la nature: Commission des Communantés européennes.

Goodman, R. C., Phillips, O. L., \& Baker, T. R. (2014). The importance of crown dimensions to improve tropical tree biomass estimates. Ecological Applications, 24, 680-698. https://doi.org/10.1890/13-0070.1

Hackenberg, J., Morhart, C., Sheppard, J., Spiecker, H., \& Disney, M. (2014). Highly accurate tree models derived from terrestrial laser scan data: A method description. Forests, 5, 1069-1105. https://doi.org/10.3390/ f5051069

Hackenberg, J., Spiecker, H., Calders, K., Disney, M., \& Raumonen, P. (2015). SimpleTree - An efficient open source tool to build tree models from TLS clouds. Forests, 6, 4245-4294. https://doi.org/10.3390/f6114245

Hackenberg, J., Wassenberg, M., Spiecker, H., \& Sun, D. (2015). Non destructive method for biomass prediction combining TLS derived tree volume and wood density. Forests, 6, 1274-1300. https://doi. org/10.3390/f6041274

Hosoi, F., Nakai, Y., \& Omasa, K. (2013). Voxel tree modeling for estimating leaf area density and woody material volume using 3-D LIDAR data. ISPRS Annals of Photogrammetry, Remote Sensing and Spatial Information Sciences, II-5/W2, 115-120. https://doi.org/10.5194/ isprsannals-II-5-W2-115-2013

Houghton, R. A., Byers, B., \& Nassikas, A. A. (2015). A role for tropical forests in stabilizing atmospheric CO2. Nature Climate Change, 5, 10221023. https://doi.org/10.1038/nclimate2869 
Kaasalainen, S., Krooks, A., Liski, J., Raumonen, P., Kaartinen, H., Kaasalainen, M., ... Mäkipää, R. (2014). Change detection of tree biomass with terrestrial laser scanning and quantitative structure modelling. Remote Sensing, 6, 3906-3922. https://doi.org/10.3390/rs6053906

van Leeuwen, M., \& Nieuwenhuis, M. (2010). Retrieval of forest structural parameters using LiDAR remote sensing. European Journal of Forest Research, 129, 749-770. https://doi.org/10.1007/s10342-010-0381-4

Letouzey, R. (1985). Notice de la carte phytogéographique du Cameroun au 1 500 000. Institut de la Carte Internationale de la Végétation.

Maniatis, D., Malhi, Y., Saint André, L., Mollicone, D., Barbier, N., Saatchi, S., ... White, L. (2011). Evaluating the potential of commercial forest inventory data to report on forest carbon stock and forest carbon stock changes for REDD+ under the UNFCCC. International Journal of Forestry Research, 2011, 1-13. https://doi. org/10.1155/2011/134526

Mei, J., Zhang, L., Wu, S., Wang, Z., \& Zhang, L. (2017). 3D tree modeling from incomplete point clouds via optimization and L1-MST. International Journal of Geographical Information Science, 31, 999-1021. https://doi.org/10.1080/13658816.2016.1264075

Momo Takoudjou, S., Ploton, P. M., Sonké, B., Hackenberg, J., Griffon, S., de Coligny, F., ... Barbier, N. (2017). Data from: Using Terrestrial Laser Scanning data to estimate large tropical trees biomass and calibrate allometric models: A comparison with traditional destructive approach. Dryad Digital Repository, https://doi.org/10.5061/dryad.10hq7

Muggeo, V. M. R. (2003). Estimating regression models with unkown breakpoints. Statistics in Medicine, 22, 3055-3071. https://doi.org/10.1002/ (ISSN)1097-0258

Nogueira, E. M., Fearnside, P. M., Nelson, B. W., Barbosa, R. I., \& Keizer, E. W. H. (2008). Estimates of forest biomass in the Brazilian Amazon: New allometric equations and adjustments to biomass from wood-volume inventories. Forest Ecology and Management, 256, 1853-1867. https:// doi.org/10.1016/j.foreco.2008.07.022

Nölke, N., Fehrmann, L., Jaya, I. N. S., Tiryana, T., Seidel, D., \& Kleinn, C. (2015). On the geometry and allometry of big-buttressed trees - A challenge for forest monitoring: New insights from 3D-modeling with terrestrial laser scanning. IForest, 8, 574-581. https://doi.org/10.3832/ ifor1449-007

Olagoke, A., Proisy, C., Féret, J. B., Blanchard, E., Fromard, F., Mehlig, U., ... Berger, U. (2016). Extended biomass allometric equations for large mangrove trees from terrestrial LiDAR data. Trees - Structure and Function, 30, 935-947. https://doi.org/10.1007/s00468-015-1334-9

Picard, N., Boyemba Bosela, F., \& Rossi, V. (2015). Reducing the error in biomass estimates strongly depends on model selection. Annals of Forest Science, 72, 811-823. https://doi.org/10.1007/s13595-014-0434-9

Picard, N., \& Saint-andré, L. (2012). Manuel de construction d 'équations allométriques pour I 'estimation du volume et la biomasse des arbres. Centre de Coopération Internationale en Recherche Agronomique pour le Développement, Food and Agriculture Organization of the United Nations, Rome, Italy, 224.

Ploton, P., Barbier, N., Momo, S. T., Rejou-Mechain, M., Boyemba Bosela, F., Chuyong, G., ... Pélissier, R. (2016). Closing a gap in tropical forest biomass estimation: Taking crown mass variation into account in pantropical allometries. Biogeosciences, 13, 1571-1585. https://doi. org/10.5194/bg-13-1571-2016

R Development Core Team. (2015). R Internals. R Development Core Team, 1, 63.

Rahman, M. Z. A., Bakar, M. A. A., Razak, K. A., Rasib, A. W., Kanniah, K. D., Kadir, W. H. W., ... Latif, Z. A. (2017). Non-destructive, laser-based individual tree aboveground biomass estimation in a tropical rainforest. Forests, 8, 86. https://doi.org/10.3390/f8030086

Raumonen, P., Casella, E., Calders, K., Murphy, S., Åkerbloma, M., \& Kaasalainen, M. (2015). Massive-scale tree modelling from TLS data. ISPRS Annals of Photogrammetry, Remote Sensing and Spatial Information Sciences, II-3/ W4, 189-196. https://doi.org/10.5194/isprsannals-II-3-W4-189-2015

Raumonen, P., Kaasalainen, M., Åkerblom, M., Kaasalainen, S., Kaartinen, H., Vastaranta, M., ... Lewis, P. (2013). Fast automatic precision tree models from terrestrial laser scanner data. Remote Sensing, 5, 491-520. https://doi.org/10.3390/rs5020491

Rochon, P. (2014). PypeTree: A tool for reconstructing tree perennial tissues from point clouds. Sensors, 14, 4271-4289.

Stovall, A. E. L., Vorster, A. G., Anderson, R. S., Evangelista, P. H., \& Shugart, H. H. (2017). Non-destructive aboveground biomass estimation of coniferous trees using terrestrial LiDAR. Remote Sensing of Environment, 200, 31-42. https://doi.org/10.1016/j.rse.2017.08.013

Tansey, K., Selmes, N., Anstee, A., Tate, N. J., \& Denniss, A. (2009). Estimating tree and stand variables in a Corsican Pine woodland from terrestrial laser scanner data. International Journal of Remote Sensing, 30, 5195-5209. https://doi.org/10.1080/01431160902882587

Tao, S., Guo, Q., Xu, S., Su, Y., Li, Y., \& Wu, F. (2015). A geometric method for wood-leaf separation using terrestrial and simulated lidar data. Photogrammetric Engineering \& Remote Sensing, 81, 767-776. https:// doi.org/10.14358/PERS.81.10.767

Tao, S., Wu, F., Guo, Q., Wang, Y., Li, W., Xue, B., ... Fang, J. (2015). Segmenting tree crowns from terrestrial and mobile LiDAR data by exploring ecological theories. ISPRS Journal of Photogrammetry and Remote Sensing, 110, 66-76. https://doi.org/10.1016/j.isprsjprs.2015.10.007

Torr, P. H. S., \& Zisserman, A. (2000). MLESAC: A new robust estimator with application to estimating image geometry. Computer Vision and Image Understanding, 78, 138-156. https://doi.org/10.1006/cviu.1999.0832

Trochta, J., Kruček, M., Vrška, T., \& Kraâl, K. (2017). 3D Forest: An application for descriptions of three-dimensional forest structures using terrestrial LiDAR. PLoS ONE, 12, e0176871. https://doi.org/10.1371/ journal.pone.0176871

Wilkes, P., Lau, A., Disney, M., Calders, K., Burt, A., Gonzalez de Tanago, J., ... Herold, M. (2017). Data acquisition considerations for terrestrial laser scanning of forest plots. Remote Sensing of Environment, 196, 140153. https://doi.org/10.1016/j.rse.2017.04.030

Zanne, A. E., Lopez-Gonzalez, G., Coomes, D. A. A., llic, J., Jansen, S., Lewis, S. L. S. L., ... Chave, J. (2009). Global wood density database. Dryad Digital Repository, 235, 33.

\section{SUPPORTING INFORMATION}

Additional Supporting Information may be found online in the supporting information tab for this article.

How to cite this article: Momo Takoudjou S, Ploton P, Sonké B, et al. Using terrestrial laser scanning data to estimate large tropical trees biomass and calibrate allometric models: A comparison with traditional destructive approach. Methods Ecol Evol. 2018;9:905-916. https://doi.org/10.1111/2041210X.12933 